\title{
Prediction of SOFC Performance with or without Experiments: A Study on Minimum Requirements for Experimental Data
}

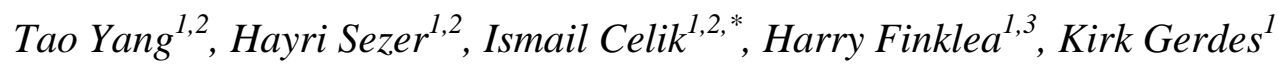 \\ ${ }^{1}$ National Energy Technology Laboratory, Morgantown, WV 26507, United States \\ ${ }^{2}$ Mechanical and Aerospace Engineering Department, West Virginia University, Morgantown, WV \\ 26506, United States \\ ${ }^{3}$ C. Eugene Bennett Department of Chemistry, West Virginia University, Morgantown, WV 26506, \\ United States \\ *E-mail: Ismail.Celik@mail.wvu.edu
}

doi: $10.20964 / 2017.07 .30$

Received: 3 May 2016 / Accepted: 17 January 2017 / Published: 12 June 2017

\begin{abstract}
In the present study, experiments and multi-physics simulations are utilized together to analyze and predict the polarization curves and impedance behavior of solid oxide fuel cells (SOFCs). This new procedure consists of experiments, empirical polarization analysis, and multi-physics numerical simulations. First, polarization curves and impedance behavior are measured for various fuel/air utilization conditions. Then, the empirical polarization analysis is applied in conjunction with experiments to extract estimated values of essential parameters for the cell under study. Finally, numerical simulations are performed to determine/refine the model parameters via simultaneous calibration using polarization curves and impedance behavior. It is demonstrated that at least three fuel/air utilization conditions. i.e. low utilization, low air supply, and low fuel supply, are required as a complete set of data for better understanding of the processes within the cell. The cell performances at different working loads and various cell configurations are also simulated and analyzed to understand the processes in anode and cathode separately, illustrating the capability of the proposed model. The simulations, incorporating realistic material properties, provide details of overpotential and species concentration distributions within the porous electrodes for in-depth analysis. This proposed procedure can be utilized for quick diagnostics and analysis of button cells as well as planar cells made of same material without further calibration.
\end{abstract}

Keywords: Solid Oxide Fuel Cell, Electrochemical Impedance Analysis, Multi-Physics Numerical Simulation, Polarization Analysis

\section{$\underline{\text { FULL TEXT }}$}


(C) 2017 The Authors. Published by ESG (www.electrochemsci.org). This article is an open access article distributed under the terms and conditions of the Creative Commons Attribution license (http://creativecommons.org/licenses/by/4.0/). 